\title{
Cuidados voltados aos familiares de pessoas em finitude humana
}

\author{
Care aimed at family members of people in human finitude \\ Atención dirigida a familiares de personas en finitud humana
}

Recebido: 19/01/2021 | Revisado: 22/01/2021 | Aceito: 26/01/2021 | Publicado: 04/02/2021

\author{
Ana Cláudia de Queiroz \\ ORCID: https://orcid.org/0000-0002-7842-567X \\ Universidade Federal de Campina Grande, Brasil \\ E-mail: claudia.ana.queiroz@gmail.com \\ Monique Pereira da Silva \\ ORCID: https://orcid.org/0000-0002-3497-9064 \\ Universidade Federal de Campina Grande, Brasil \\ E-mail: moniquepereiragba@hotmail.com \\ Maria Clara Soares Dantas \\ ORCID: https://orcid.org/0000-0002-4206-7954 \\ Universidade Federal de Campina Grande, Brasil \\ E-mail: dantasclarinha@gmail.com \\ Andrielly Cavalcante Fonseca \\ ORCID: https://orcid.org/0000-0002-2560-0147 \\ Universidade Federal de Campina Grande, Brasil \\ E-mail: andriellycavalcante11@gmail.com \\ Débora Thaise Freires De Brito \\ ORCID: https://orcid.org/0000-0003-0346-8699 \\ Universidade Federal da Paraíba, Brasil \\ E-mail: deborathaise_@hotmail.com \\ Glenda Agra \\ ORCID: https://orcid.org/0000-0002-7628-9029 \\ Universidade Federal de Campina Grande, Brasil \\ E-mail: glenda.agra@professor.ufcg.edu.br
}

\begin{abstract}
Resumo
Objetivo: Sumarizar as contribuições da produção científica sobre os cuidados dispensados à familiares de pessoas em finitude humana. Metodologia: Trata-se de uma revisão integrativa da literatura sobre os cuidados voltados para os familiares de pacientes em processo de finitude humana. Resultados: Foram apresentadas duas categorias temáticas: Categoria temática I - Religiosidade e Espiritualidade e Categoria temática II - Redes de apoio formais e informais, que se subdividiu em três subcategorias: Subcategoria I - Apoio familiar; Subcategoria II - Comunicação efetiva a partir da equipe interdisciplinar que compõem a rede e Subcategoria III - Atenção biopsicossocial e educativa da rede. Conclusão: Os cuidadores enfrentam muitas dificuldades no processo de adoecimento do seu ente querido durante o processo de finitude humana, exigindo dos profissionais de saúde atenção à escuta, acolhimento e observação de sinais clínicos e psíquicos de sofrimento mental, como também uma comunicação de forma clara e objetiva acerca do quadro clínico do seu ente querido.
\end{abstract}

Palavras-chave: Atenção à saúde; Família; Cuidados Paliativos.

\begin{abstract}
Objective: To summarize the contributions of scientific production on the care provided to family members of people in human finitude. Methodology: This is an integrative review of the literature on care aimed at family members of patients in the process of human finitude. Results: Two thematic categories were presented: Thematic category I Religiosity and Spirituality and Thematic category II - Formal and informal support networks, which were subdivided into three subcategories: Subcategory I - Family support; Subcategory II - Effective communication from the interdisciplinary team that make up the network and Subcategory III - Biopsychosocial and educational attention of the network. Conclusion: Caregivers face many difficulties in the process of illness of their loved one during the process of human finitude, requiring health professionals to pay attention to listening, welcoming and observing clinical and psychic signs of mental suffering, as well as clear communication and objective about the clinical picture of your loved one.
\end{abstract}

Keywords: Health care; Family; Palliative Care. 


\section{Resumen}

Objetivo: Resumir los aportes de la producción científica sobre el cuidado brindado a familiares de personas en finitud humana. Metodología: Se trata de una revisión integradora de la literatura sobre el cuidado dirigido a familiares de pacientes en proceso de finitud humana. Resultados: Se presentaron dos categorías temáticas: Categoría temática I Religiosidad y espiritualidad y Categoría temática II - Redes de apoyo formales e informales, las cuales se subdividieron en tres subcategorías: Subcategoría I - Apoyo familiar; Subcategoría II - Comunicación efectiva del equipo interdisciplinario que conforma la red y Subcategoría III - Atención biopsicosocial y educativa de la red. Conclusión: Los cuidadores enfrentan muchas dificultades en el proceso de enfermedad de su ser querido durante el proceso de finitud humana, requiriendo que los profesionales de la salud presten atención a escuchar, acoger y observar los signos clínicos y psíquicos del sufrimiento mental, así como una comunicación clara. y objetivo sobre el cuadro clínico de su ser querido.

Palabras clave: Atención a la salut; Familia; Cuidados Paliativos.

\section{Introdução}

As doenças crônicas não transmissíveis (DCNT) são consideradas um problema de saúde de grande significância, correspondendo a maior carga de morbimortalidade no mundo e sendo responsáveis por $63 \%$ das mortes globais. As mortes por DCNT afetam prevalecente os países em desenvolvimento, nos quais cerca de um terço dos óbitos ocorrem em pessoas com menos de 60 anos de idade, enquanto nos países desenvolvidos a mortalidade prematura (faixa etária de 30 a 69 anos) corresponde a menos de $13 \%$ dos casos (Malta et al., 2019). As doenças crônicas não transmissíveis foram responsáveis por cerca de 56,9\% das mortes no Brasil no ano de 2017, na faixa etária de 30 a 69 anos e são consideradas um dos maiores problemas globais de saúde pública da atualidade (Brasil, 2019).

O envelhecimento, a urbanização, as mudanças sociais e econômicas e a globalização são alguns dos fatores que afetam o modo de viver, trabalhar e se alimentar da população, e como consequência, tem aumentado o número das doenças crônicas não transmissíveis (DCNTs) (Silocchi \& Junges, 2017). As pessoas com DCNT apresentam perda da qualidade de vida, alto grau de limitação para suas atividades habituais de trabalho e lazer, impacto econômico negativo para as famílias, comunidades e sociedade. Desse modo, essas pessoas necessitam de cuidados contínuos e integrais. Essas doenças quando apresentam uma progressão clínica severa, que ameace à vida, precisa ser conduzida à luz da filosofia e princípios dos cuidados paliativos (Silva, Sena, Rolim, Souza \& Sardinha, 2017).

Cuidados paliativos são cuidados holísticos ativos, ofertados a pessoas de todas as idades que se encontram em intenso sofrimento relacionado à saúde, proveniente de doença grave, especialmente aquelas que estão no final de vida. Os objetivos dos cuidados paliativos são, portanto, melhorar a qualidade de vida dos pacientes, de suas famílias e seus cuidadores. (Radbruch et al., 2020).

Uma vez abordado o tema 'cuidados paliativos' é interessante traçar algumas linhas sobre a noção de família. Família é caracterizada por um grupo de pessoas inter-relacionadas por laços de matrimônio, nascimento, adoção ou outras formas de vínculo sociais e pessoais. No modelo de cuidados paliativos, família pode ser compreendido por um sistema dinâmico de interação cuja propriedade básica é que a mudança de um dos membros, potencialmente, provoca modificações nos demais e, como consequência, redefinem-se novos sistemas a partir de mudanças (Furtado \& Leite, 2017).

A doença progressiva e incapacitante, bem como o processo de finitude humana altera todos os níveis das funções pessoais de uma pessoa, seja no aspecto familiar, laboral, econômico e social. Na família, esta situação produz uma ruptura e uma crise na vida diária com modificações em todo o seu núcleo. O medo, a insegurança, a incerteza e, muitas vezes, os sentimentos velados provocam na família e no ente que vivencia o processo de terminalidade, ansiedade e estresse. Nessa conjuntura, o enfermeiro, dentre os profissionais da saúde, é um dos que mantém uma relação mais próxima com a família, devendo assim respeitar a importância da família como, também, seus valores e crenças de modo a compreendê-los (Deon et al., 2018). 
Nesse sentido, os familiares precisam de atenção à sua saúde também, envolvendo desde os seus aspectos biopsicossociais e espirituais durante todo o processo de doença, morte e luto de seu ente querido, desde o conforto por meio de acomodações adequadas, apoio no enfrentamento de seus medos e angústias, esclarecimento dos processos inerentes ao diagnóstico, manifestações clínicas e desfecho da doença, bem como a permissão para expressar livremente seus medos, angústias, espiritualidade e quando possível, a realização de rituais específicos de sua religião (Matos \& Borges, 2018).

Com base nessa realidade, e considerando que apesar da relevância da temática, existe um quantitativo incipiente de estudos relacionados ao tema em questão, o estudo parte da seguinte questão norteadora: Qual a contribuição da produção científica sobre os cuidados voltados para os familiares de pacientes em processo de finitude humana? Portanto, o objetivo desta revisão integrativa é sumarizar as contribuições da produção científica sobre os cuidados dispensados à familiares de pessoas em finitude humana. Desse modo, entendemos ser o estudo desta temática de grande relevância para o campo da saúde, porquanto poderá estimular os profissionais a refletir sobre a necessidade de atender à família do paciente que se encontra em processo de finitude humana e que requer apoio biopsicossocial e espiritual. Também poderá subsidiar novas investigações acerca da temática, visto que o núcleo familiar no tocante à modalidade paliativa necessita ser mais explorado no âmbito acadêmico e assistencial.

\section{Metodologia}

Trata-se de um estudo qualitativo, do tipo revisão integrativa da literatura, em que consiste na elaboração de uma análise ampla da literatura, assim colaborando nas discussões sobre os métodos, os resultados de pesquisas e reflexões sobre a realização de futuros estudos. Para a realização desta, foram empregados 6 momentos: I) elaboração da pergunta norteadora; II) definição dos critérios norteadores do levantamento da produção científica nas fontes literárias; III) coleta de dados; IV) análise crítica dos estudos incluídos; V) discussão dos resultados; e VI) elaboração da síntese do conhecimento e consequente relatório de pesquisa (Souza, Vieira, Severino, \& Antunes, 2017).

Na primeira etapa, buscou-se responder à seguinte questão norteadora da pesquisa: Qual a contribuição da produção científica sobre os cuidados voltados para os familiares de pacientes em processo de finitude humana?

O levantamento da literatura foi realizado pela internet, durante o período de maio a julho de 2020. Foram estabelecidos os seguintes critérios de inclusão: estudos científicos disponíveis eletronicamente nas bases de dados disponibilizadas na Biblioteca Virtual em Saúde, artigos que abordassem a temática, dentro de todas as áreas de interesse da Enfermagem, nos idiomas inglês, espanhol e português, no espaço temporal de 2016 a 2019. Como critérios de exclusão foram considerados: publicações repetidas nas bases de dados, estudos científicos não disponíveis na íntegra e artigos que não fizessem alusão aos cuidados dispensados a familiares de pessoas em finitude humana.

Para a busca dos estudos, utilizaram-se as bases de dados: Literatura Internacional em Ciências da Saúde (MEDLINE), Centro Latino-Americano e do Caribe de Informações em Ciêncais da Saúde (LILACS), Base de Dados em Enfermagem (BDENF), Scientific Library Online (SciELO) com os seguintes descritores "atenção à saúde"; "família"; "cuidados paliativos"; "health care"; "family"; "palliative care"; "atención a la salut"; "familia" e "cuidados paliativos", utilizando o operador booleano AND.

Inicialmente, dirigiu-se à apreciação do título, resumo e descritores que abordassem o fenômeno, conforme o número de publicações descrito nas bases de dados: MEDLINE, LILACS, BDENF, SciELO 114 em inglês, 17 em português e 6 em espanhol). Esta etapa inclui um processo de organização e reorganização de ideias e informações essenciais colhidas na literatura, as quais se tornam importantes para orientar o pesquisador quando ao modo de definir e medir cada característica fundamental na composição do fenômeno. Despois de uma leitura flutuante desses artigos observou-se que 02 eram repetidos 23 não faziam alusão aos familiares de pessoas em finitude humana. Após essa etapa, procedeu-se à leitura na íntegra desses 
artigos utilizando os critérios de inclusão e exclusão supracitados. Assim, fizeram parte da amostra 18 artigos, sendo 12 em inglês, 5 em português e 1 em espanhol.

A leitura do material foi realizada pelos pesquisadores, de forma independente. A fase de discussão dos principais resultados encontrados nos artigos ocorreu por meio de sucessivas análises e reflexões sobre as contribuições sobre os cuidados voltados para os familiares de pacientes em processo de finitude humana.

\section{Resultados}

Na presente revisão integrativa da literatura, analisaram-se 16 artigos que atenderam aos critérios de inclusão e exclusão previamente estabelecidos. As informações extraídas de cada um dos artigos foram: título do periódico, base de dados, ano de publicação, título do artigo, objetivo, principais conclusões que estão dispostas no Quadro 1, logo a seguir. Posteriormente, direcionou-se à extração específica dos cuidados voltados à familiares de pessoas em finitude humana.

Quadro 1 - Distribuição das informações extraídas dos artigos da amostra.

\begin{tabular}{|c|c|c|c|c|c|c|}
\hline & $\begin{array}{l}\text { Título do } \\
\text { periódico }\end{array}$ & $\begin{array}{ll}\text { Bases } & \text { de } \\
\text { dados } & \end{array}$ & $\begin{array}{l}\text { Ano de } \\
\text { publica } \\
\text { ção }\end{array}$ & Título do artigo & Objetivo & Principais conclusões \\
\hline A1 & $\begin{array}{l}\text { Psycho- } \\
\text { oncology }\end{array}$ & MEDLINE & 2015 & $\begin{array}{l}\text { Short-term and long-term } \\
\text { effects of a psycho-educational } \\
\text { group intervention for family } \\
\text { caregivers in palliative home } \\
\text { care - results from a } \\
\text { randomized control trial. } \\
\text { (Efeitos a curto e longo prazo } \\
\text { de um processo } \\
\text { psicopedagógico Intervenção } \\
\text { em grupo para cuidadores } \\
\text { familiares em casa paliativa } \\
\text { resultado de um estudo } \\
\text { randomizado de controle). }\end{array}$ & $\begin{array}{l}\text { Avaliar a curto e } \\
\text { longo prazo efeitos de } \\
\text { uma intervenção } \\
\text { psicoeducativa em } \\
\text { grupo com o objetivo } \\
\text { de aumentar a } \\
\text { preparação para o } \\
\text { cuidado familiar em } \\
\text { cuidados paliativos } \\
\text { domiciliares } \\
\text { especializados. }\end{array}$ & $\begin{array}{l}\text { A intervenção psicoeducativa } \\
\text { tem potencial para ser } \\
\text { utilizada para melhorar a } \\
\text { preparação no cuidado entre } \\
\text { cuidadores familiares em } \\
\text { cuidados paliativos, tanto em } \\
\text { curto e longo prazo. }\end{array}$ \\
\hline A 2 & $\begin{array}{l}\text { Revista } \\
\text { Cubana de } \\
\text { Medicina } \\
\text { General } \\
\text { Integral }\end{array}$ & LILACS & 2016 & $\begin{array}{l}\text { Caracterización del cuidador } \\
\text { primario de enfermo oncológico } \\
\text { en estado avanzado. } \\
\text { (Caracterização do cuidador } \\
\text { primário de enfermo oncológico } \\
\text { em estado avançado). }\end{array}$ & $\begin{array}{l}\text { Caracterizar o } \\
\text { cuidador informal e os } \\
\text { aspectos oncológicos } \\
\text { que contribuem para a } \\
\text { qualidade do } \\
\text { atendimento } \\
\text { domiciliar. }\end{array}$ & $\begin{array}{lr}\text { Predominância } & \text { da } \\
\text { necessidade de } & \text { orientação } \\
\text { para CP domiciliares, sendo } \\
\text { os cuidadores satisfeitos } \\
\text { aqueles com } \text { maior } \\
\text { representação. Instrução, } \\
\text { aconselhamento, treinamento, } \\
\text { aplicação de guias medidas } \\
\text { psicoeducacionais e de alívio } \\
\text { são aspectos essenciais na } \\
\text { qualidade do atendimento } \\
\text { domiciliar. }\end{array}$ \\
\hline A3 & $\begin{array}{l}\text { Texto } \\
\text { Contexto } \\
\text { Enferm, }\end{array}$ & LILACS & 2016 & $\begin{array}{l}\text { Dificuldades de cuidadores de } \\
\text { pacientes em cuidados } \\
\text { paliativos na estratégia da saúde } \\
\text { da família. }\end{array}$ & $\begin{array}{lr}\text { Desvelar as principais } \\
\text { dificuldades } \\
\text { enfrentadas } \\
\text { cuidadores relos } \\
\text { pacientes em ruidados } \\
\text { paliativos } & \text { de } \\
\text { domicílio } & \text { e } \\
\text { compreender } & \text { a } \\
\text { percepção } & \text { dos } \\
\text { mesmos em relação } \\
\text { ao suporte oferecido } \\
\text { pela estratégia da } \\
\text { saúde da família. }\end{array}$ & $\begin{array}{l}\text { Dificuldades atreladas à falta } \\
\text { de rede de apoio, de recursos } \\
\text { humanos, materiais, } \\
\text { financeiros e ao despreparo } \\
\text { para lidar com a morte no } \\
\text { contexto da terminalidade } \\
\text { refletindo o despreparo } \\
\text { pessoal aliadas à precariedade } \\
\text { social e econômica. }\end{array}$ \\
\hline
\end{tabular}




\begin{tabular}{|c|c|c|c|c|c|c|}
\hline A4 & $\begin{array}{l}\text { Palliative } \\
\text { Medicine }\end{array}$ & MEDLINE & 2016 & $\begin{array}{l}\text { Carers of people affected by } \\
\text { cancer and other long-term } \\
\text { conditions at end of life: A } \\
\text { qualitative study of providing a } \\
\text { bespoke package of support in a } \\
\text { rural setting. } \\
\text { (Cuidadores de pessoas afetadas } \\
\text { por câncer e outras condições } \\
\text { de longo prazo no final da vida } \\
\text { útil: um estudo qualitativo sobre } \\
\text { a prestação de pacote de apoio } \\
\text { em um ambiente rural). }\end{array}$ & $\begin{array}{l}\text { Descrever } \\
\text { experiências } \\
\text { qualitativas dos } \\
\text { cuidadores } \\
\text { recebem a intervenção } \\
\text { (pacote personalizado } \\
\text { de suporte). }\end{array}$ & $\begin{array}{l}\text { A intervenção foi bem- } \\
\text { sucedida em um ambiente de } \\
\text { assistência social. Sentiram } \\
\text { uma sensação de } \\
\text { tranquilidade por terem apoio } \\
\text { prévio e relatou que a } \\
\text { situação teria sido pior se esse } \\
\text { apoio não existisse. }\end{array}$ \\
\hline A5 & $\begin{array}{l}\text { Journal of } \\
\text { Paediatric } \\
\text { s and } \\
\text { Child } \\
\text { Health }\end{array}$ & MEDLINE & 2016 & $\begin{array}{l}\text { Respite needs of families } \\
\text { receiving palliative care. } \\
\text { (Respeitar as necessidades das } \\
\text { famílias que recebem cuidados } \\
\text { paliativos). }\end{array}$ & $\begin{array}{l}\text { Descrever os tipos de } \\
\text { cuidados temporários } \\
\text { que as famílias } \\
\text { recebem. }\end{array}$ & $\begin{array}{l}\text { Há uma variedade entre os } \\
\text { cuidados temporários, } \\
\text { principalmente em trégua } \\
\text { noturna, havendo variação no } \\
\text { intervalo ideal. E falta de } \\
\text { provedores capacitados para } \\
\text { viabilizar o cuidado. }\end{array}$ \\
\hline A6 & $\begin{array}{l}\text { Psycho- } \\
\text { oncology }\end{array}$ & MEDLINE & 2016 & $\begin{array}{l}\text { Factors associated with quality } \\
\text { of life among Family caregivers } \\
\text { of terminally ill cancer patients. } \\
\text { (Fatores associados a qualidade } \\
\text { de vida na família cuidadores de } \\
\text { pacientes com câncer terminal). }\end{array}$ & $\begin{array}{l}\text { Investigar } \text { os } \\
\text { determinantes da } \\
\text { qualidade de vida em } \\
\text { geral e seus } \\
\text { subdomínios entre as } \\
\text { CFS coreanos no final } \\
\text { da vida. }\end{array}$ & $\begin{array}{l}\text { O sofrimento emocional das } \\
\text { CFs foi o mais importante no } \\
\text { quadro geral e aspectos } \\
\text { negativos da QV dos CFs. A } \\
\text { adaptação positiva esteve } \\
\text { relacionada a mais visitas de } \\
\text { assistência, religiosidade dos } \\
\text { cuidadores familiares, mais } \\
\text { apoio social, e qualidade } \\
\text { percebida satisfatória dos } \\
\text { cuidados. }\end{array}$ \\
\hline A7 & $\begin{array}{l}\text { Revista } \\
\text { Cuidarte }\end{array}$ & $\begin{array}{l}\text { BDENF - } \\
\text { Enfermage } \\
\mathrm{m}\end{array}$ & 2017 & $\begin{array}{l}\text { Espiritualidade de famílias com } \\
\text { um ente querido em situação de } \\
\text { final de vida. }\end{array}$ & $\begin{array}{l}\text { Compreender o papel } \\
\text { da espiritualidade na } \\
\text { vida de famílias que } \\
\text { possuem um ente em } \\
\text { situação de final de } \\
\text { vida. }\end{array}$ & $\begin{array}{l}\text { Religião e espiritualidade } \\
\text { ajudam no enfrentamento do } \\
\text { cuidado com entes no final da } \\
\text { vida. }\end{array}$ \\
\hline A8 & Wiley & MEDLINE & 2017 & $\begin{array}{l}\text { Participation and interest in } \\
\text { support services among Family } \\
\text { caregivers of older adults with } \\
\text { câncer. } \\
\text { (Participação e interesse em } \\
\text { serviços de apoio à família } \\
\text { cuidadores de idosos com } \\
\text { câncer). }\end{array}$ & $\begin{array}{lr}\text { Descrever o uso e } \\
\text { interesse } & \text { de } \\
\text { cuidadores familiares } \\
\text { angustiados } & \text { e } \\
\text { despreparados } & \text { em } \\
\text { serviços formais de } \\
\text { apoio. }\end{array}$ & $\begin{array}{l}\text { Uma grande proporção de } \\
\text { cuidadores familiares não está } \\
\text { usando serviços de apoio } \\
\text { formal, mas têm um grande } \\
\text { interesse em serviços. }\end{array}$ \\
\hline A9 & $\begin{array}{l}\text { Palliative } \\
\text { and } \\
\text { Supportiv } \\
\text { e Care }\end{array}$ & MEDLINE & 2017 & $\begin{array}{l}\text { Identifying and addressing the } \\
\text { support needs of family } \\
\text { caregivers of people with motor } \\
\text { neurone disease using the Carer } \\
\text { Support Needs Assessment } \\
\text { Tool. (Identificando e } \\
\text { atendendo as necessidades de } \\
\text { suporte de cuidadores familiares } \\
\text { de pessoas com doença do } \\
\text { neurônio motor usando o Care } \\
\text { Support Needs Assessment } \\
\text { Ferramenta). }\end{array}$ & $\begin{array}{l}\text { Avaliar a viabilidade } \\
\text { e a relevância da } \\
\text { ferramenta de de } \\
\text { avaliação } \\
\text { necessidades de } \\
\text { suporte ao cuidador } \\
\text { (CSNAT) no cuidado } \\
\text { domiciliar durante o } \\
\text { período do cuidado na } \\
\text { perspectiva dos } \\
\text { cuidadores familiares } \\
\text { de pessoas com MND } \\
\text { e seus prestadores de } \\
\text { serviços. }\end{array}$ & $\begin{array}{l}\text { As necessidades de apoio dos } \\
\text { cuidadores foram } \\
\text { consideradas relevantes e } \\
\text { viáveis pelos cuidadores } \\
\text { familiares MND e consultores } \\
\text { de cuidados sendo a } \\
\text { ferramenta um facilitador das } \\
\text { discussões e, assim, } \\
\text { possibilitando que estas sejam } \\
\text { atendidas. }\end{array}$ \\
\hline A 10 & $\begin{array}{l}\text { Oncology } \\
\text { Nursing } \\
\text { Forum }\end{array}$ & MEDLINE & 2017 & $\begin{array}{l}\text { Living With Hepatocellular } \\
\text { Carcinoma Near the End of } \\
\text { Life: Family Caregivers }\end{array}$ & $\begin{array}{l}\text { Explorar as } \\
\text { perspectivas dos } \\
\text { cuidadores familiares } \\
\text { de cuidar de pacientes }\end{array}$ & $\begin{array}{l}\text { Os cuidadores familiares } \\
\text { experimentaram incerteza e se } \\
\text { sentiram despreparados para } \\
\text { fornecer cuidados adequados }\end{array}$ \\
\hline
\end{tabular}




\begin{tabular}{|c|c|c|c|c|c|c|}
\hline & & & & $\begin{array}{l}\text { perspectives. } \\
\text { (Viver com carcinoma } \\
\text { hepatocelular perto do fim da } \\
\text { vida: perspectivas de cuidadores } \\
\text { familiares). }\end{array}$ & $\begin{array}{l}\text { com carcinoma } \\
\text { hepatocelular terminal } \\
\text { (CHC) a medida que } \\
\text { os pacientes se } \\
\text { aproximavam do fim } \\
\text { da vida. }\end{array}$ & $\begin{array}{l}\text { à medida que o paciente se } \\
\text { aproximava do fim de sua } \\
\text { vida. }\end{array}$ \\
\hline A11 & $\begin{array}{l}\text { Palliative } \\
\text { Medicine }\end{array}$ & MEDLINE & 2018 & $\begin{array}{l}\text { Caregiver quality of life in } \\
\text { advanced cancer: Qualitative } \\
\text { results from a trial of early } \\
\text { palliative care. } \\
\text { (Qualidade de vida do cuidador } \\
\text { em nível avançado de câncer: } \\
\text { resultados qualitativos de um } \\
\text { estudo de cuidados paliativos } \\
\text { precoces). }\end{array}$ & $\begin{array}{l}\text { Conceituar a } \\
\text { qualidade de vida dos } \\
\text { cuidadores a partir de } \\
\text { sua própria } \\
\text { perspectiva e explorar } \\
\text { as diferenças de temas } \\
\text { entre os que } \\
\text { receberam ou não } \\
\text { uma intervenção } \\
\text { precoce em cuidados } \\
\text { paliativos. }\end{array}$ & $\begin{array}{l}\text { A qualidade de vida do } \\
\text { cuidador é influenciada pela } \\
\text { interação com o paciente e } \\
\text { pode ser medida com } \\
\text { questionários que incluem } \\
\text { conteúdos relacionados ao } \\
\text { enfrentamento da mortalidade } \\
\text { e apoios profissionais. Os } \\
\text { participantes do grupo de } \\
\text { intervenção engajados em } \\
\text { uma discussão equilibraram } \\
\text { esperança com realismo e } \\
\text { aumentou a confiança de } \\
\text { vários profissionais. }\end{array}$ \\
\hline A12 & $\begin{array}{l}\text { Rev } \\
\text { enferm } \\
\text { UFPE }\end{array}$ & $\begin{array}{l}\text { BDENF - } \\
\text { Enfermage } \\
\mathrm{m}\end{array}$ & 2018 & $\begin{array}{l}\text { Experiências de cuidadores nos } \\
\text { cuidados paliativos e redes de } \\
\text { suporte. }\end{array}$ & $\begin{array}{l}\text { Compreender as } \\
\text { experiências } \\
\text { vivenciadas as por } \\
\text { cuidadores familiares } \\
\text { de pacientes elegíveis } \\
\text { para cuidados } \\
\text { paliativos. }\end{array}$ & $\begin{array}{l}\text { Vivenciaram-se importantes } \\
\text { mudanças em suas rotinas } \\
\text { diárias, ocasionando uma } \\
\text { sobrecarga física e mental, } \\
\text { levando à necessidade de } \\
\text { redes de apoio formais e } \\
\text { informais para estes cuidados. } \\
\text { Há inexistência de rede de } \\
\text { apoio formal aos cuidadores e } \\
\text { a falta de treinamento e } \\
\text { orientação suficientes para } \\
\text { realização do cuidado. }\end{array}$ \\
\hline A13 & $\begin{array}{l}\text { Enferm } \\
\text { Foco }\end{array}$ & $\begin{array}{l}\text { LILACS, } \\
\text { BDENF - } \\
\text { Enfermage } \\
\mathrm{m}\end{array}$ & 2019 & $\begin{array}{l}\text { Rede de apoio e sustentação dos } \\
\text { cuidadores familiares de } \\
\text { pacientes em cuidados } \\
\text { paliativos no domicílio. }\end{array}$ & $\begin{array}{lr}\text { Conhecer } & \text { a rede } \\
\text { apoio e } & \text { sustentação } \\
\text { dos } & \text { cuidadores } \\
\text { familiares } & \text { de } \\
\text { pacientes em ruidados } \\
\text { paliativos } & \text { no } \\
\text { domicílio. } & \end{array}$ & $\begin{array}{l}\text { A maior parte dos cuidadores } \\
\text { assumiu o cuidado por se } \\
\text { sentir obrigado. Entre as redes } \\
\text { de apoio, a família ora foi a } \\
\text { mais citada como unidade } \\
\text { colaboradora, ora como rede } \\
\text { não participativa. }\end{array}$ \\
\hline A14 & $\begin{array}{l}\text { Palliative } \\
\text { Medicine }\end{array}$ & MEDLINE & 2019 & $\begin{array}{l}\text { The experience of family } \\
\text { caregivers of patients with } \\
\text { cancer in an Asian country: A } \\
\text { grounded theory approach. (A } \\
\text { experiência dos familiares de } \\
\text { pacientes com câncer em uma } \\
\text { região asiática do país: uma } \\
\text { abordagem da teoria } \\
\text { fundamentada). }\end{array}$ & $\begin{array}{l}\text { Explorar e modelar } \\
\text { experiências r de } \\
\text { cuidadores familiares } \\
\text { de pacientes com } \\
\text { câncer na Indonésia } \\
\text { na execução de tarefas } \\
\text { do cuidar. }\end{array}$ & $\begin{array}{l}\text { As crenças e espiritualidade } \\
\text { são vistas como importantes } \\
\text { no processo de cuidar diante } \\
\text { do enfrentamento do câncer. }\end{array}$ \\
\hline A15 & $\begin{array}{l}\text { Journal of } \\
\text { cardiovasc } \\
\text { ular } \\
\text { nursing }\end{array}$ & MEDLINE & 2019 & $\begin{array}{l}\text { Inadequate Communication } \\
\text { Exacerbates the Support Needs } \\
\text { of Current and Bereaved } \\
\text { Caregivers in Advanced Heart } \\
\text { Failure and Impedes Shared } \\
\text { Decision-making. } \\
\text { (Exacerbação inadequada da } \\
\text { comunicação as necessidades de } \\
\text { apoio dos atuais e enlutados } \\
\text { cuidadores em insuficiência } \\
\text { cardíaca avançada e impede a } \\
\text { tomado de decisão } \\
\text { compartilhada). }\end{array}$ & $\begin{array}{l}\text { Explorar } r \\
\text { experiência dos } \\
\text { cuidadores ao cuidar } \\
\text { de um ente querido } \\
\text { com insuficiência } \\
\text { cardíaca avançada no } \\
\text { final de vida para } \\
\text { identificar quaisquer } \\
\text { necessidades } \\
\text { psicossociais não } \\
\text { atendidas. }\end{array}$ & $\begin{array}{l}\text { Necessidade de comunicação } \\
\text { clara e objetiva sobre o } \\
\text { diagnóstico e prognóstico } \\
\text { para efetivação do cuidado. }\end{array}$ \\
\hline A16 & $\begin{array}{l}\text { Rev Fun } \\
\text { Care }\end{array}$ & $\begin{array}{l}\text { LILACS, } \\
\text { BDENF }\end{array}$ & 2019 & $\begin{array}{lrr}\text { Juntos resistimos, } & \text { separados } \\
\text { caímos: } & \text { vivências } & \text { familiares } \\
\end{array}$ & $\begin{array}{l}\text { Descrever } \\
\text { experiência }\end{array}$ & $\begin{array}{l}\text { Experiências de sofrimento na } \\
\text { jornada de acompanhamento }\end{array}$ \\
\hline
\end{tabular}




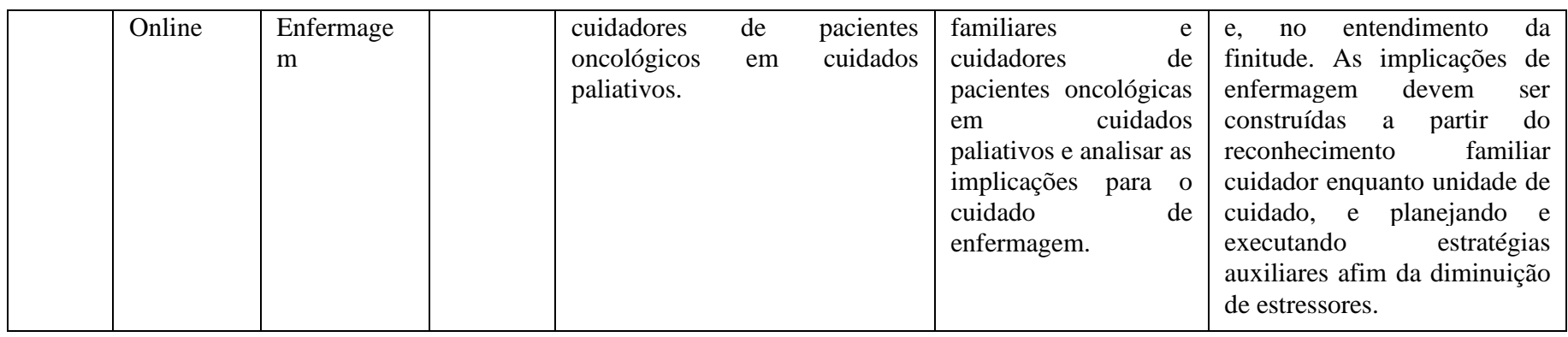

Fonte: Dados da pesquisa (2021).

Ao analisar os objetivos e os principais resultados dos artigos incluídos na revisão, observa-se, de maneira geral, que o cuidar de um familiar em processo de finitude humana pode acarretar riscos para a saúde física e psicológica do cuidador, por este motivo o apoio de outras pessoas, assim como ter acesso a recursos sociais e psicológicos são fundamentais para os cuidadores de pessoas em finitude humana.

\section{Discussão}

Após leituras sucessivas dos estudos selecionados para a presente revisão e o agrupamento de informações, foi possível construir duas categorias temáticas: Categoria temática I - Religiosidade e Espiritualidade e Categoria temática II Redes de apoio formais e informais, que se subdividiu em três subcategorias: Subcategoria I - Apoio familiar; Subcategoria II - Comunicação efetiva a partir da equipe interdisciplinar que compõem a rede e Subcategoria III - Atenção biopsicossocial e educativa da rede.

\subsection{Categoria temática I - Religiosidade e Espiritualidade}

No campo dos cuidados paliativos, o cuidado em saúde deve considerar os aspectos biopsicossociais e espirituais não apenas dos pacientes em finitude humana, mas também de seus familiares, uma vez que a espiritualidade é um elemento fundamental perante o sofrimento e as dificuldades enfrentadas em situações de terminalidade da vida (Kristanti et al., 2016; Miqueletto et al., 2017).

Alguns estudos que fazem parte da amostra (Choi et al., 2016; Kristanti et al., 2016; Miqueletto et al., 2017; Cardoso et al, 2019; Lima et al, 2019) evidenciaram que os familiares reconhecem a importância da espiritualidade e religiosidade no enfrentamento das dificuldades que o momento vivenciado os impõe. Nessa perspectiva, tentam encontrar meios que aumentem as possibilidades de resoluções perante o sofrimento, e diante disso, buscam ressignificar a dimensão espiritual, com intuito de compreender o sentido da vida e alcançar uma dimensão superior que possibilite o amadurecimento e o crescimento pessoal.

É oportuno frisar que espiritualidade e religiosidade, apesar de serem conceitos relacionados, não são sinônimos. A espiritualidade é a dimensão peculiar de todo ser humano e o impulsiona na busca do sagrado, da experiência transcendente na tentativa de dar sentido e resposta aos aspectos fundamentais da vida. A religiosidade é expressão ou prática do crente que pode estar relacionada com uma instituição religiosa. Esta possibilita ao sujeito experiências místicas, mágicas e esotéricas. Nesse ínterim, vale ressaltar que religião é um termo proveniente do latim "religio" e "ligare”, que significa ligar de novo, compreendendo a busca de Deus por parte das pessoas. As religiões têm como base um aspecto misterioso e cativante, no sentido de apoderar o ser humano na ideia de haver algo que é sentido no cotidiano da existência humana que é transcendental (Miqueletto et al., 2017; Curcio \& Almeida, 2019). 
Nessa conjuntura, estudo de Choi et al. (2016) apontou que familiares que prestaram cuidados a entes queridos em terminalidade perceberam-se como pessoas úteis ao oferecerem mais tempo e energia durante o processo de cuidado, bem como apontam a religiosidade e espiritualidade como fatores potenciais para à adaptação positiva durante essa fase da vida.

A espiritualidade, por estar relacionada ao sagrado, é considerada uma estratégia que aumenta a fé, possibilitando, assim, melhor controle interno frente à experiência de finitude humana, bem como estimula a esperança no enfrentamento da doença, da morte e do luto; além de servir como um processo de constante aprendizado e superação, que oferece lógica e coerência em situações de doença e morte (Miqueletto et al., 2017; Arrieira, 2017).

Os estudos de Kristanti et al. (2016) e Miqueletto et al. (2017) evidenciaram que os familiares encontraram forças para enfrentar as dificuldades quando lhes foi proporcionado espaços de diálogos sobre Deus e espiritualidade e a oração foi a prática religiosa mais realizada pelos familiares, as quais trouxeram sensação de paz, saúde, felicidade e proteção. Diante disso, observou-se que durante o processo de cuidar, as práticas de oração ocorreram com maior frequência e intensidade do que os familiares costumavam fazer antes de se tornarem cuidadores. Observou-se também que alguns familiares que praticavam meditação e realizavam orações tiveram melhor qualidade de vida e responderam positivamente frente a todo processo de adoecimento e finitude humana de seu ente querido. (Arrieira et al, 2017).

Já o estudo de Kristanti et al. (2016) observou que familiares apontaram ausência de espaços para diálogos sobre espiritualidade com os profissionais de saúde. Nesse sentido, é primordial que os profissionais de saúde reconheçam a importância do papel dos familiares durante este processo e ofertem uma assistência humanizada, não ignorando a dimensão espiritual, uma vez que o cuidado espiritual cabe a todos os envolvidos e o apoio ofertado aumenta a capacidade de enfrentar os desafios, principalmente quando se considerado os costumes, valores e crenças dos cuidadores (Cervelin \& Luce Kruse, 2015; Miqueletto et al., 2017).

Estudo de Cervelin e Luce Kruse (2015) elencou alguns critérios que auxiliam os profissionais de saúde para a realização de uma assistência espiritual eficaz, a saber: respeitar a crença espiritual, realizar escuta qualificada, ter empatia e ofertar apoio, reconhecer ao sofrimento do outro e permitir visitas de capelães e prestadores de cuidados espirituais.

Levando em consideração que a espiritualidade e a religiosidade foram elencadas pelos familiares como mecanismos de enfrentamento construtivo perante o processo de cuidado de seus entes queridos em finitude humana, constituindo-se como aspectos essenciais para o fortalecimento da dimensão espiritual desses indivíduos, uma vez que a espiritualidade e a religiosidade ajudam a dar significado às experiências de sofrimento e morte (Choi et al., 2016; Kristanti et al., 2016; Miqueletto et al., 2017; Cardoso et al., 2019; Lima et al., 2019).

\subsection{Categoria temática II - Redes de apoio formais e informais}

\subsubsection{Subcategoria I - Apoio familiar}

As famílias contemporâneas são estruturadas de formas diversas e dinâmicas, sendo constituídas por indivíduos que fazem parte de determinado núcleo familiar regido pelo fator da consanguinidade eou pela convivência e afinidade, em que seguem regras e normas que ordenam as relações interpessoais, que determinam os papéis de cada membro e estabelecem os limites e as alianças desse núcleo (Espíndola et al., 2018).

Por ser a primeira rede de apoio social dos indivíduos, as famílias são entendidas como um espaço de suporte para o enfrentamento das dificuldades impostas pela vida, o que pode gerar sentimentos de pertencimento, cuidado e estima e possibilitar recursos emocionais para lidar com situações adversas que exigem mudanças e readaptação das regras e relações familiares, como situações em que o indivíduo se encontra adoecido e vulnerável pela aproximação do fim da vida (Vazquez et al., 2016; Espíndola et al., 2018; Cardoso et al., 2019). 
Pacientes em finitude de vida, geralmente, possuem o desejo de receberem cuidados no domicílio e isso requer um cuidador principal e uma rede de apoio familiar. Vale salientar que, de acordo com estudos de Choi et al., (2015); Vázquez et al. (2016); Pessalacia et al. (2018); Lima et al. (2019); Cardoso et al. (2019), o cuidador principal é, na maioria das vezes, um familiar próximo do paciente (cônjugue ou filho) e do sexo feminino, que também requer atenção, pois se constitui como um agente prestador e receptor de cuidados e que assume essa responsabilidade, muitas vezes, abdicando da própria vida (Holm et al., 2015; Meneguini \& Ribeiro, 2016).

Nessa perspectiva, estudos de Meneguini e Ribeiro (2016); Kristanti et al. (2019); Lima et al. (2019) evidenciaram que alguns cuidadores principais de pacientes em CP possuíam dificuldades de encontrar apoio dos demais familiares, seja pela ausência de solidariedade ou pelo fato destes familiares considerarem que o cuidador principal é o mais qualificado para acompanhar o ente querido, devido às ligações de afeto e reciprocidade entre ambos. Além disso, os outros membros da família acreditam que o cuidado deve ser ofertado por cônjuges ou filhos por uma questão de obrigação moral e cultural. O cuidador principal desempenha um papel primordial no tratamento de pacientes em finitude humana, principalmente quando a doença progride, pois além de prestar um cuidado direto ao ente querido, também ajuda na reorganização e manutenção das relações familiares (Vázquez et al., 2016; Aoun et al., 2017; McDonald et al., 2018).

Nestas situações, a família pode ser considerada como unidade colaboradora ou pode consistir em uma rede não participativa. Nos casos em que a rede familiar é não participativa, o cuidador principal que assume esse papel isoladamente, se sobrecarrega e tem múltiplos impactos em sua vida. E por estarem sobrecarregados, tendem a não executar o cuidado de forma adequada, o que torna imprescindível o apoio familiar para qualidade do cuidado e da vida do cuidador (Pessalacia et al., 2018; Cardoso et al., 2019).

Estudos da amostra (Auon et al., 2017; McDonald et al., 2018; Pessalacia et al., 2018; Fitzsimons et al., 2019; Lima et al., 2019) apontaram que cuidadores principais que não têm apoio dos demais familiares, costumam experienciar significativa sobrecarga física, emocional, psicológica, social, financeira e existencial, impactando assim, na dinâmica familiar.

A sobrecarga física do cuidador principal está relacionada à responsabilidade diária do ente querido e observada por sintomas como exaustão, insônia, estresse, preocupação constante com a morte, depressão, solidão, medo, culpa e sensação de fracasso, o que impacta em sua qualidade de vida e na assistência ao seu ente querido (Pessalacia et al., 2018; Fitzsimons et al., 2019; Kristanti et al., 2019).

A sobrecarga emocional do cuidador principal está relacionada à incerteza da trajetória da doença, bem como da evolução do processo de finitude humana. Geralmente, sentem-se impotentes frente à situação vivenciada, gerando quadros de estresse e ansiedade. Além disso, observou-se que o tempo dispensado no cuidado ao ente querido fez com que o cuidador principal apresentasse um déficit de autocuidado, no que se relaciona ao repouso, sono, alimentação, socialização, o que gerou perda de energia e esgotamento físico e mental. Vale mencionar que a maioria dos cuidadores principais foram obrigados a realizar horas-extras no emprego para suprir as necessidades da carga horária laboral e/ou sentiram-se obrigados a pedir demissão e/ou fecharam seu próprio empreendimento para cuidarem em tempo integral dos seus entes queridos, o que impactou financeiramente nas relações familiares. Muitos cuidadores são obrigados a fazer horas extras no emprego para suprir as necessidades do ente querido ou pedir demissão do trabalho e até mesmo fechar o próprio empreendimento para ofertar cuidados em tempo integral, o que gera impacto financeiro e consequentemente, mudanças marcantes em sua vida. Com todas essas dimensões abaladas, o próprio processo de cuidar, torna-se fragilizado (Choi et al., 2015; Meneguin \& Ribeiro et al., 2016; Aoun et al., 2017; Hansen et al., 2017; McDonald et al., 2018; Kristanti et al., 2019; Lima et al., 2019).

Neste contexto, observou-se que a atenção ao cuidador principal, por vezes, é negligenciada ou pouco valorizada pelos demais familiares, sendo a maior fonte de conflitos na relação de cuidado, em virtude de fatores como relações difíceis entre paciente-cuidador-familiares e a ausência de colaboração nas tarefas diárias de cuidado impostas pela doença, o que 
sobrecarrega este cuidador, contribuindo para que este não priorize as suas próprias necessidades (Meneguin \& Ribeiro et al., 2016; Aoun et al., 2017).

O estudo de Kristanti et al. (2019) evidenciou que as relações interpessoais também podem ser afetadas por altas expectativas da família em relação aos cuidados prestados pelo cuidador principal, gerando conflitos. Nesta perspectiva, é fundamental que a família compartilhe os cuidados, dividindo as tarefas e contribuindo da melhor maneira possível, seja financeiramente, seja dedicando mais tempo e energia para o processo de cuidar.

Além disso, a família deve buscar ajuda nas redes de apoio, sejam formais (instituições de saúde e religiosas) ou informais (amigos, vizinhos, organizações não governamentais), para colaborar com o cuidador principal uma vez que essa ajuda é indispensável para minimizar os impactos gerados pela sobrecarga e auxiliar no enfrentamento dos desafios provenientes da situação em que o ente querido (Aoun et al., 2017; Pessalacia et al., 2018; Lima et al., 2019; Cardoso et al., 2019).

Por necessitar que outros familiares auxiliem no processo de cuidar, o cuidador principal deve distribuir a assistência de forma equitativa, aceitar ajuda de outros familiares, amigos e vizinhos que se adequem à dinâmica familiar e manifestem o desejo de apoiá-lo, contribuindo assim, para a diminuição de conflitos provenientes das relações interpessoais e das dificuldades advindas da doença. Além disso, compartilhar cuidado proporciona ao ente querido possibilidades para aumentar suas interações sociais (Vázquez et al., 2016; Smith, Graham \& Herbert, 2016; Cardoso et al., 2019).

Nessa perspectiva, observa-se que os impactos que o processo de doença e de terminalidade causa na vida dos cuidadores principais podem ser minimizados quando o cuidado é compartilhado com os demais familiares, a partir da divisão das atividades diárias. Entretanto, é oportuno enfatizar que sejam identificadas as demandas não apenas do cuidador principal, mas também dos demais familiares, agregando as expectativas de cada um e a disponibilidade para lidar com os desafios da situação, para que exista um equilíbrio e, consequentemente melhora das relações interpessoais dos envolvidos no processo de cuidar (Vázquez et al., 2016; Smith, Graham \& Herbert, 2016; Aoun et al., 2017; Pessalacia et al., 2018; Kristanti et al., 2019; Lima et al., 2019; Cardoso et al., 2019).

\subsubsection{Subcategoria II - Comunicação efetiva a partir da equipe interdisciplinar da rede}

Comunicação é o ato de interagir e partilhar informações com outras pessoas por meio de mensagens que podem ser emitidas e recebidas através de sinais (verbais e não verbais), a fim de se fazer compreender e alcançar o objetivo pelo qual foi iniciada a discussão. Desse modo, a linguagem não verbal dá-se através de sons, gestos, expressões faciais, motricidade corpórea, enquanto a verbal dá-se por meio da fala ou da escrita (Santos \& Silva, 2016; Brocai \& Ferreira, 2018).

Quando a equipe interdisciplinar comunicação verbal e não verbal de forma adequada, por meio de escuta atenta, de olhar afetuoso e de atitudes empáticas proporciona à família um leque de possibilidades de participar na tomada de decisões e cuidados específicos relacionados à doença do seu ente querido (Andrade, Costa \& Lopes, 2013).

Nos CP, a comunicação é uma ferramenta fundamental para se atender às inquietações dos familiares sobre a situação do ente querido e compreender suas demandas biopsicossociais e espirituais. Diante disso, é primordial que a equipe interdisciplinar priorize um momento de comunicação prévia com o cuidador principal na admissão do paciente na assistência paliativa com intuito de prepará-lo para situação, sobretudo para o processo de morte (Varquez et al., 2016; Hansen et al., 2017; Lima et al., 2019).

A comunicação efetiva é um direito do paciente em finitude humana e da sua família e uma grande necessidade dos familiares, pois necessitam ser mantidos informados sobre o que acontece e sobre o que esperar do processo de morte e morrer de seus entes. Deste modo, uma das necessidades mais proeminentes da família é o estabelecimento de uma comunicação clara, honesta e frequente com os membros da família que cuidam do paciente (Varquez et al. 2016; Fitzsimons et al., 2019). 
Cabe ressaltar que más notícias são informações difíceis que modificam as perspectivas de futuro do paciente e do cuidador familiar, sendo imprescindível que sejam relatadas de forma clara e empática, para que sejam compreendidas pelo receptor. Entretanto, antes de relatar notícias difíceis é importante avaliar as características sociais, culturais e emocionais do cuidador familiar, para decidir o conteúdo e a forma de relatar, oportunizando também o mesmo se expressar verbalmente ou por meio de gestos (Lima et al., 2019).

As habilidades de comunicação são adquiridas pelos profissionais a partir de uma adequada capacitação e treinamento em serviço, podendo contribuir positivamente na qualidade de vida dos familiares, a partir do momento em que valorizam também os valores das pessoas envolvidas nesse processo (Meneguini \& Ribeiro, 2016).

Nessa perspectiva, a equipe interdisciplinar deve dominar as três grandes artes da comunicação: a arte de perguntar, de escutar e de observar sustentadas pelo princípio da verdade desejável, verdade suportável e confidencialidade da informação. Perguntar, escutar e observar se constituem ações primordiais para que ocorra a compreensão das necessidades dos familiares, as quais são, na maioria das vezes, o acompanhamento e apoio emocional e o desejo por informações verdadeiras sobre a situação do ente querido (Vázquez et al., 2016).

Contudo, os estudos de Nelson, Mansfield r Kane (2016); Hansen et al. (2017); Fitzsimons et al. (2019) apontaram que a maioria dos familiares de pacientes em finitude humana relataram pouco conhecimento sobre a doença pouco ou nenhum conhecimento sobre cuidados básicos e específicos; sentiam-se desamparados e expressaram o desejo de obter informações efetivas dos profissionais de saúde para compreender melhor a situação e fornecer o cuidado adequado, uma vez que se baseavam em fontes alternativas como a internet.

O estudo de Fitzsimons et al. (2019) mostrou que familiares enlutados relataram que não houve comunicação efetiva durante o processo de adoecimento e morte e morrer do ente querido, o que gerou má compreensão dos aspectos clínicos da doença, e, consequentemente tomadas de decisões equivocadas, bem como aborrecimentos, medo, culpa e frustração. Diante disso, consideraram que a trajetória de morte iminente é, muitas vezes, uma experiência solitária e que a assistência ao cuidador não deve cessar durante a fase de luto precoce.

É essencial que os profissionais de saúde apoiem os familiares ao longo da trajetória da doença do ente querido, incluindo a fase de morte até o luto, fornecendo informações claras e contínuas com intuito de reduzir níveis de estresse, desentendimentos com a equipe e conflitos familiares (Fitzsimons et al., 2019; Nelson, Mansfield \& Kane, 2016).

Nesse sentido, vale destacar a importância da habilidade adequada do profissional para relatar más notícias aos familiares, pois é uma tarefa difícil, mas inevitável, que exige preparo antecipado, empatia, segurança e conhecimento dos valores culturais, sociais, espirituais e emocionais de quem a está recebendo (Varquez et al., 2016).

Dessa forma, não é possível compreender o impacto da notícia em sua profundidade, entretanto, acolher o familiar, ofertar uma escuta qualificada e possibilitar a construção do conhecimento no fazer diário, valorizando a singularidade e potencialidade de cada cuidador-são condutas essenciais nos cuidados paliativos (Lima et al., 2019).

\subsubsection{Subcategoria III - Atenção biopsicossocial e educativa da rede}

As Redes de Atenção à Saúde (RAS) são definidas como arranjos organizativos de ações e serviços de saúde, de diferentes densidades tecnológicas, que integradas por meio de sistemas de apoio técnico, logístico e de gestão, buscam garantir o acesso aos serviços de saúde, a equidade e a integralidade do cuidado (Brasil, 2010).

Nessa perspectiva, as equipes de saúde da família da Atenção Primária a Saúde (APS), consideradas portas de entrada prioritárias dos usuários na rede, devem acompanhar os pacientes em finitude humana e os cuidadores familiares de seu território de abrangência, por meio de um cuidado longitudinal, resguardados pelos demais áreas de abrangência da RAS, como a atenção domiciliar, ambulatorial, de urgência e emergência e a hospitalar (Brasil, 2018). 
Nos momentos finais da vida de um ente querido, é comum que familiares recorram à ajuda deste espaço como meio de suporte para o enfrentamento da doença do ente querido, pela possibilidade dos profissionais ofertarem um cuidado longitudinal e mais próximo de onde vivem, além da facilidade em se manterem em comunicação contínua, estabelecer vínculo e confiança e proporcionar um acompanhamento humanizado nesse processo de morte (Meneguini \& Ribeiro, 2016; Pessalacia et al., 2018; Cardoso et al., 2019).

Diante disso, é extremamente importante que a equipe interdisciplinar esteja capacitada para esse tipo de cuidado, uma vez que o esforço físico, a pressão emocional, as restrições sociais e as demandas econômicas, geralmente, geram sobrecarga nesses cuidadores (Meneguini \& Ribeiro, 2016; Vázquez et al., 2016).

É oportuno enfatizar que as redes de apoio contribuem no enfrentamento da sobrecarga dos familiares gerada pelos cuidados contínuos aos seus entes. As entidades religiosas, os parentes e profissionais de unidades de saúde da APS são considerados como referência de suporte emocional, momentos de descanso e de atividades recreativas aos-familiares (Pessalacia et al., 2018)

Entretanto, estudos (Holm et al., 2015; Hansen et al., 2017; Kristanti et al., 2019) apontaram que alguns familiares se sentiram despreparados e inseguros para cuidar dos entes queridos em terminalidade de vida dificuldades em relação ao transporte intermunicipal; à acomodação quando acompanharam os entes ao hospital; na realização de alguns procedimentos diagnósticos e na aquisição de medicamentos, necessitando da ajuda de outros familiares e parentes para suprirem essas necessidades.

Sobre estas dificuldades, é imperioso mencionar que a Resolução $\mathrm{N}^{\circ}$ 41, de 31 de Outubro de 2018, que dispõe sobre as diretrizes para a organização dos cuidados paliativos, à luz dos cuidados continuados integrados, no âmbito Sistema Único de Saúde (SUS), ressalta em seu artigo $5^{\circ}$ que os cuidados paliativos deverão ser ofertados em qualquer ponto da rede de atenção à saúde, notadamente: I - Atenção Básica; II - Atenção Domiciliar; III - Atenção Ambulatorial; IV - Urgência e Emergência; V - Atenção Hospitalar; em seu artigo $7^{\circ}$, ressalta que o acesso aos medicamentos [...] deverá seguir as normas sanitárias vigentes e observar as pactuações entre as instâncias de gestão do SUS e em seu artigo $8^{\circ}$, destaca que o financiamento para a organização dos CP deverá ser objeto de pactuação tripartite, observando o planejamento e a organização dos cuidados continuados integrados na RAS (Brasil, 2018).

Estudos (Meneguini \& Ribeiro et al., 2016; Pessalacia et al., 2018) observaram que há fragilidades no treinamento de profissionais da APS como rede de apoio formal, uma vez que familiares relataram receber poucas visitas dos profissionais e quando recebiam, limitavam-se à verificação da necessidade de medicação ou receita médica em detrimento da necessidade de orientação e supervisão de cuidados específicos durante o processo de morte.

A ausência de capacitação dos profissionais de saúde em CP tem dificultado a articulação da RAS, uma vez que as instituições de formação em saúde abordam os $\mathrm{CP}$ de forma fragmentada e com ênfase nas ações de recuperação da saúde e isso acaba impactando no treinamento e orientação da assistência que devem ser prestadas pelos cuidadores em domicílio. Nessa perspectiva, ressalta-se a importância do papel de familiares serem treinados para cuidar do ente querido, uma vez que a manutenção do bem-estar do paciente exige a execução de múltiplas tarefas (Pessalacia et al., 2018).

Além do apoio prático, os familiares necessitam de apoio físico e psicossocial para suportar as demandas de cuidado durante o processo de morte e luto. Por isso, é indispensável que a equipe interdisciplinar realize uma avaliação diagnóstica da situação biopsicossocial e espiritual do paciente e dos familiares, para que intervenções sejam planejadas com o intuito de contribuir para melhoria da qualidade de vida de ambos e para adaptação dos demais familiares envolvidos no processo de cuidar, proporcionando uma rede de apoio flexível (Meneguini \& Ribeiro, 2016).

É primordial apresentar aos familiares os serviços disponibilizados pelas redes de apoio, para que possam ter conhecimento e acessem quando precisarem, pois estudo o Dionne-Odom et al. (2017) apontou que os cuidadores 
demonstraram grande interesse em acessar os serviços de apoio formal e aqueles que frequentaram esses serviços sentiam-se preparados para executar a função de cuidador e tinham baixo grau de sensação de sobrecarga.

No estudo de Dionne-Odom et al (2017), as principais barreiras para acessar os serviços de apoio formal enfatizadas pelos familiares foram: o estigma em relação aos serviços de saúde mental; sentimento de culpa por focar em suas próprias necessidades acreditando que prejudicariam as necessidades do ente querido; ausência de percepção do seu sofrimento ou por acreditarem que os problemas mentais devem ser geridos por eles próprios, sem ajuda de profissionais.

A melhoria dos serviços de cuidados paliativos e do acesso dos cuidadores a estes, desde o início da prestação de cuidados até o luto contribuem para redução da sobrecarga física e emocional e consequentemente melhoram a qualidade de vida do cuidador. Reconhecer a contribuição dos cuidadores e apoiá-los de forma eficiente, com melhores informações, identificação precoce de suas necessidades para ofertar intervenções psicossociais e disponibilidade de serviços de suporte é indispensável (Fitzsimons et al, 2019).

Os familiares podem acessar serviços formais de apoio como aconselhamento profissional ou de pares, assistência domiciliar, grupos de apoio, workshops de treinamento e cuidados temporários, sendo essencial a disponibilidade de momentos educativos e processos de triagem para os cuidadores durante o atendimento clínico de rotina dos pacientes em finitude humana, visando à identificação precoce dos cuidadores que necessitam de apoio formal (Dionne-Odom, et al., 2017; McDonald et al., 2017).

Estudo (Aoun et al., 2017) evidenciou que as cinco principais necessidades de apoio relatadas por cuidadores familiares foram: perspectivas para o futuro; ter uma referência para entrar em contato em momentos de preocupação; possuir equipamentos para auxiliar no cuidado ao paciente; lidar com sentimentos e preocupações e ter tempo para cuidar de si durante o dia.

Para enfrentar os desafios provenientes do processo de terminalidade, os cuidadores relataram manterem-se informados sobre a doença, ter atitudes positivas, estreitar as relações afetivas, construir uma rede de apoio para o autocuidado por meio de técnicas de meditação e exercícios e diminuir a tensão por meio da fé religiosa. Ter treinamento com conselheiro de luto também foi apontado como uma estratégia positiva para o enfretamento do momento (McDonald et al., 2017).

Treinamentos e guias psicoeducacionais são considerados ferramentas que auxiliam os familiares a enfrentarem dificuldades durante a prestação do cuidado e a desenvolverem habilidades que permitam melhor funcionamento social (Vázquez et al., 2016). Nessa perspectiva, um estudo (Holm et al., 2015) evidenciou que intervenções psicoeducativas têm demonstrado resultados positivos na vida de cuidadores familiares, aumentando significativamente a preparação e competência destes para cuidarem adequadamente dos problemas relacionados à doença de seu ente querido, bem como possibilita o compartilhamento de experiências.

As ações de educação em saúde são indispensáveis para compreensão dos familiares sobre a assistência que deve ser prestada ao paciente em finitude humana, a qual deve ser realizada de forma compartilhada, valorizando a diversidade de saberes e o nível de entendimento do cuidador, pois o baixo nível de instrução pode dificultar a compreensão de algumas práticas de cuidado e conhecimento sobre sinais e sintomas da doença, sendo importante esse apoio educativo (Cardoso et al., 2019; Lima et al., 2019).

Estudo de Cardoso et al., (2019) identificou redes de apoio que amparam os cuidadores familiares de pacientes em cuidados paliativos por meio da utilização de ferramentas como o genograma e ecomapa na APS. Com isso, foi possível sumarizar a intensidade das relações dos cuidadores com serviços de saúde, igrejas, trabalho, bem como compreender melhor as relações familiares. A partir dessas ferramentas, os profissionais podem contribuir no fortalecimento dessas redes de apoio e, consequentemente, reduzir a sobrecarga do cuidador familiar (Cardoso et al., 2019). 
É crucial ressaltar que existem estratégias para identificar a necessidade de apoio ao familiar de forma sistemática, como a "Ferramenta de Avaliação de Necessidades de Apoio ao Cuidador (CSNAT)", que facilita o diálogo entre o profissional e o cuidador, levando-o a refletir sobre suas próprias necessidades e a reconhecer a importância do seu papel no cuidado e nas questões de fim de vida (Aoun et al., 2017).

Diante disso, o CSNAT ajuda a fornecer uma abordagem holística às necessidades dos familiares, uma vez que possibilita um processo de acompanhamento estruturado e contínuo, em que as necessidades do cuidador são registradas e seu acompanhamento pode ser realizado por contato telefônico, conforme prática habitual (Aoun et al., 2017).

Nessa perspectiva, é essencial que a equipe interdisciplinar que presta assistência aos familiares de pacientes em finitude humana, os apoie durante o processo de cuidar e na fase de luto precoce, avaliem suas necessidades biopsicossociais e espirituais e ofereçam suporte educativo, por meio de uma linguagem clara e efetiva, para que estes sejam estimulados a ter confiança e resiliência durante a prestação de cuidados e, consequentemente, satisfação de cuidar de seu ente querido (Vásquez et al., 2016; McDonald et al., 2017).

\section{Conclusão}

O estudo em tela possibilitou sumarizar as contribuições da produção científica sobre os cuidados dispensados à familiares de pacientes em cuidados paliativos. Nesse sentido foi possível identificar aspectos que interferem negativamente na dinâmica da rotina diária, bem como na assistência ao ente querido, como a sobrecarga física e mental, levando à necessidade de apoio de redes formais e informais durante e após a prestação desses cuidados.

Um dos aspectos ressaltados foi a escassez de espaços para diálogos sobre espiritualidade com os profissionais de saúde em relação ao paciente e ao próprio familiar. Nesta perspectiva, vale ressaltar que para além dos cuidados básicos do paciente e aqueles em seu entorno, existem cuidados que não atendem às necessidades do corpo físico, mas amplia para outras dimensões do ser. Desse modo, é essencial que os profissionais de saúde promovam o cuidado espiritual, tais como: estimular a fé e a crença dos pacientes e familiares; preservar o momento religioso e/ou espiritual do paciente e familiares; estimular a busca de conexão com o sagrado; solicitar serviço de capelania; estabelecer vínculo e confiança; utilizar estratégias como música e meditação como ferramentas para reflexão da vida.

Outro aspecto mencionado foi a declinação de outros membros da família no que se refere à divisão de tarefas no cuidado ao familiar nas diversas etapas do processo de adoecimento, morte e morrer e luto, o que impactou em sobrecarga física, emocional, social e espiritual do cuidador principal.

Nesta perspectiva, a equipe multiprofissional deve, antes de qualquer intervenção, avaliar o modo como a família está enfrentando todo o processo de finitude humana, bem como seu funcionamento ao longo dessa experiência. Desse modo, por meio de uma boa avaliação com base nas principais necessidades e preocupações da família, é possível traçar algumas intervenções como: buscar apoio de outros familiares, implicando-os também no cuidado, reconhecendo e valorizando o trabalho do cuidador principal e favorecendo a aproximação; facilitar a visita e o acesso das crianças e membros da família, servindo de intermediário para a despedida do ente querido; integrar outros membros da família no processo de tomada de decisões; utilizar recursos sociais disponíveis sempre que necessário e fomentar a intimidade e o diálogo para resolver problemas pendentes.

A fragilidade na comunicação verbal e não verbal da equipe com os cuidadores também foi um dos aspectos destacados pelos estudos encontrados Vale enfatizar que a informação contínua e acessível aos familiares é o elemento essencial que permitirá uma vivência mais serena e mais tranquila no processo de finitude do ente querido, sem gerar expectativas que não podem ser atendidas. Nesta perspectiva, é indispensável que os profissionais de saúde mantenham os familiares informados com notícias claras, honestas e frequentes sobre o que acontece e sobre o que esperar do processo de 
finitude do seu ente; estejam mais presentes frequentemente; verbalizem disponibilidade, compaixão e pesar pela perda; perguntar ao familiar sobre as suas necessidades para os momentos finais; respeitar crenças, rituais e expressão de sentimentos e utilizar toque afetivo.

O último aspecto salientado foi a fragilidade da rede de apoio no que se refere à educação biopsicossocial. Nesse sentido, é primordial que a equipe da rede de apoio apresente aos familiares os serviços disponibilizados para que possam ter conhecimento e acessem quando precisarem. No entanto, é necessário que os profissionais de saúde se atualizem técnica e cientificamente; frequentem reuniões técnicas para discussão de casos mais difíceis; participem de reuniões de suporte e apoio emocional; avaliem sua disponibilidade emocional para o cuidado, bem como manter constante o exercício de não entrar em um funcionamento automático de cuidado.

No que tange às limitações do estudo, destaca-se que a produção do conhecimento científico foi oriunda de uma revisão integrativa da literatura, não havendo aproximação com os sujeitos envolvidos nas pesquisas, o que possibilitaria dados mais robustos.

Outro aspecto limitante relaciona-se à generalização dos cuidados voltados aos familiares de pacientes em finitude humana relativos ao estudo desenvolvido. Assim, caberiam novos estudos em contextos específicos nas diversas áreas e espaços de saúde em que são realizados os cuidados paliativos, visando ampliar novos espaços de discussão e articulações entre as experiências dos familiares e suas práticas de cuidado.

Apesar dessas limitações, os resultados apontados podem subsidiar novas pesquisas acerca dos cuidados voltados a familiares de pessoas não só em finitude humana, mas desde o diagnóstico, processo da doença, terminalidade do paciente e luto, especialmente no Brasil onde a produção científica é incipiente. Com efeito, espera-se que este estudo sirva como aporte para que profissionais de saúde ressignifiquem a sua prática como ação transformadora consciente e que possam contribuir eticamente à cultura do cuidado e atenção aos familiares de pessoas em cuidados paliativos e também para que se gere interfaces com as políticas públicas de saúde vigente.

Sugere-se que novos estudos sejam realizados acerca da temática, sobretudo, estudos que gerem maior força de evidência, com vistas a subsidiar a prática de cuidados paliativos no que se refere à atenção voltada para cuidadores formais e informais de pessoas em processo de finitude humana.

\section{Referências}

Andrade, C. G., Costa, S. F. G., \& Lopes, M. E. L. (2013). Cuidados paliativos: a comunicação como estratégia de cuidado para o paciente em fase terminal. Ciências \& Saúde coletiva, 18(9), 2523-30. https://doi.org/10.1590/S1413-81232013000900006.

Aoun, S. M., Deas, K., Kristjanson, L. J., \& Kissane, D. W. (2017). Identifying and addressing the support needs of family caregivers of people with motor neurone disease using the Carer Support Needs Assessment Tool. Palliative And Supportive Care, 15(1), 32-43. https://doi.org/10.1017/S1478951516000341.

Arrieira, I. C. O., Thoferhn, M. B., Schaefer, O. M., Fonseca, A. D., Kantorski, L. P., \& Cardoso, D. H. (2017). O sentido do cuidado espiritual na integralidade da atenção em cuidados paliativos. Revista Gaúcha Enfermagem. 38(3). https://doi.org/10.1590/1983-1447.2017.03.58737.

Brasil. Ministério da Saúde. Portaria de n. 4.279, de 30 de dezembro de 2010. Estabelece diretrizes para a organização da rede de atenção à saúde no âmbito do sistema único de saúde (SUS). Brasília: Ministério da Saúde, 2010. <http://bvsms.saude.gov.br/bvs/saudelegis/gm/2010/prt4279_30_12_2010.html>.

Brasil. Ministério da Saúde. Resolução n. 41, de 31 de outubro de 2018. Dispõe sobre as diretrizes para a organização dos cuidados paliativos, à luz dos cuidados continuados integrados, no âmbito Sistema Único de Saúde (SUS). Diário Oficial da União, 225(1), 276, 2018. <https://www.in.gov.br/materia//asset_publisher/Kujrw0TZC2Mb/content/id/51520746/do1-2018-11-23-resolucao-n-41-de-31-de-outubro-de-2018-51520710>.

Brasil. Ministério da saúde. Secretária de vigilância em saúde. Panorama da vigilância de doenças crônicas não transmissíveis no Brasil, 2019. <https://portalarquivos2.saude.gov.br/images/pdf/2019/marco/13/Panorama-da-Vigilancia-Epidemiologica-das-DCNT-no-Brasil.pdf>.

Brocai, P. V., \& Ferreira, M. A. (2018). A comunicação da equipe de enfermagem de uma enfermaria de clínica médica. Revista Brasileira Enfermagem, 71(3), 951-8. http://dx.doi.org/10.1590/0034-7167-2017-0208.

Cardoso, A. C., Noguez, P. T., Oliveira, S. G., Porto, A. R., Perboni, J. S., \& Farias, T. A. (2019). Rede de apoio e sustentação dos cuidadores familiares de pacientes em cuidados paliativos no domicílio. Enfermagem Foco. 10(3), 34-9. <file:///C:/Users/Igor/Downloads/1792-14054-1-PB\%20(1).pdf>. 
Cervelin, A. F., \& Luce Kruse, M. H. (2015). Espiritualidade e religiosidade nos cuidados paliativos: produzindo uma boa morte. Revista Enfermagem UFPE on line, 9(3), 7615-24. http://dx.doi.org/10.5205/reuol.7049-61452-1-ED.0903supl201515.

Choi, Y. S., Hwang, S. W., Hwang, I. C., Lee, Y. J., Kim, Y. S., Hyo Min Kim, H. M. et al. (2016). Factors associated with quality of life among family caregivers of terminally ill cancer patients. Psycho-Oncology 25(2), 217-24. http://dx.doi.org/10.1002/pon.3904.

Curcio, C. S. S., \& Almeida, A. M. (2019). Investigação dos conceitos de religiosidade e espiritualidade em amostra clínica e não clínica em contexto brasileiro: uma análise qualitativa. Interação em Psicologia, 23(02), 281-292. <file:///C:/Users/Igor/Downloads/65434-270893-1-PB.pdf>.

Deon, R. A., Medeiros, S. P., Salgado, R. G. F., Vieira, N. R., Oliveira, A. C. C., \& Abreu, D. P. G. (2018). Estratégias de cuidado familiar frente à terminalidade da vida. Revista Enfermagem UFPE on line, 12(7), 2039-49. https://doi.org/10.5205/1981-8963-v12i7a231376p2039-2049-2018.

Dionne-odom, J. N., Applebaum, A. J., Ornstein, K. A., Azuero, A., Warren, P. P., Taylor, R. A et al. (2018). Participation and interest in support services among family caregivers of older adults with câncer. Psycho-Oncology. 27(3), 969-76. https://doi.org/10.1002/pon.4603.

Espíndola A.V., Quintana, A. M., Farias, C. P., \& München, M. A. B. (2018). Relações familiares no contexto dos cuidados paliativos. Revista Bioét, 26(3), 371-7. https://doi.org/10.1590/1983-80422018263256.

Fitzsimons, D., Doherty, L. C., Murphy, M., Dixon, L., Donnelly, P., McDonald, K et al. (2019). Inadequate communication exacerbates the support needs of current and bereaved caregivers in advanced heart failure and impedes shared secision-making. Journal of Cardiovascular Nursing, 34(1), 11-9. https://doi.org/10.1097/JCN.0000000000000516.

Furtado, M. E. M. F., \& Leite, D. M. C. (2017). Cuidados paliativos sob a ótica de familiares de pacientes com neoplasia de pulmão. Comunicação, Saúde e Educação, 21(63), 969-80. http://dx.doi.org/10.1590/1807-57622016.0582.

Hansen, L., Rosenkranz, S. J., Wherity, K., Sasaki, A., Cancer, L., \& Caregivers. (2017). Living with hepatocellular carcinoma near the end of life: family caregivers' perspectives. Oncology Nursing Fórum, 44(5), 562-70. https://doi.org/10.1188/17.ONF.562-570.

Holm, M., Årestedt, K., Carlander, I., Fürst, C. J., Yvonne Wengström, Y., Öhlen, J. et al. (2015). Short-term and long-term effects of a psycho-educational group intervention for family caregivers in palliative home care - results from a randomized control trial. Psycho-Oncology, 25(7), 795-802. https://doi.org/10.1002/pon.4004.

Kristanti, M. S., Effendy, C., Utarini, A., Vernooij-Dassen, M., \& Engels, Y. (2019). The experience of family caregiversof patients with cancer in an Asian country: A grounded theory approach. Palliative Medicine, 33(6), 676-84. https://doi.org/10.1177/0269216319833260.

Lima, L. D. E. S., Santana, M. E., Júnior, A. J. S. C., \& Vasconcelos, E. V. (2019). Juntos resistimos, separados caímos: vivências de familiares cuidadores de pacientes oncológicos em cuidados paliativos. Revista Cuidado é Fundamental. 11(4), 931-36. https://doi.org/10.9789/2175-5361.2019.v11i4.931-936.

Malta, D. C., Andrade, S. S. C. A., Oliveira, T. P., Moura, L., Prado, R. R., \& Souza, M. F. M. (2019). Probabilidade de morte prematura por doenças crônicas não transmissíveis, Brasil e regiões, projeções para 2025. Revista Brasileira de Epidemiologia, 22(0). http://dx.doi.org/10.1590/1980-549720190030.

Matos, J. C., \& Borges, M. S. (2018). A família como integrante da assistência em cuidado paliativo. Revista Enfermagem UFPE, 12(9), 2399-406. https://doi.org/10.5205/1981-8963-v12i10a234575p2399-2406-2018.

McDonald, J., Swami, N,. Pope, A., Hales, S., Nissim, R., Rodin, Get al. (2018). Caregiver quality of life in advanced cancer: qualitative results from a trial of early palliative care. Palliative Medicine, 32(1), 69-78. https://doi.org/10.1177/0269216317739806.

Meneguin, S., \& Ribeiro, R. (2016). Dificuldades de cuidadores de pacientes em cuidados Paliativos na estratégia da saúde da família. Texto Contexto Enfermagem, 25(1). http://dx.doi.org/10.1590/0104-0707201500003360014.

Miqueletto, M., Silva, L., Figueira, C. B., Santos, M. R., Szylit, R., \& Ichikawa, C. R. (2017). Espiritualidade de famílias com um ente querido em situação de final de vida. Revista Cuidarte. 8(2), 1616-27. http://dx.doi.org/10.15649/cuidarte.v8i2.391.

Nelson, D., Mansfield, P., \& Kane, R. (2016). Carers of people affected by cancer and other long-term conditions at end of life: a qualitative study of providing a bespoke package of support in a rural setting. PalliativeMedicine, 31(2), 158-61. http://dx.doi.org/10.1177/0269216316648073.

Pessalacia, J. D. R., Silva, A. E., Araújo, D. H. Q., Lacerda, M. A., \& Santos, K. C. (2018). Experiências de cuidadores nos cuidados paliativos e redes de suporte. Revista Enfermagem UFPE, 12(11), 2916-22. https://doi.org/10.5205/1981-8963-v12i11a236208p2916-2922-2018.

Radbruch, L., Lima, L., Knaul, F., Wenk, R., Ali, Z., \& Bhatnaghar, S et al. (2020). Redefining palliative careda new consensus-based definition. Journal of Pain and Symptom Management, 60(4), 754-764. https://doi.org/10.1016/j.jpainsymman.2020.04.027.

Santos, T. D., \& Silva, M. A. A. (2016). Comunicação não verbal com profissionais da voz: o que se pesquisa na fonoaudiologia. Revista Cefac. 18(6), 14471455. https://doi.org/10.1590/1982-021620161865116.

Silocchi, C., \& Junges, J. Q. (2017). Equipes de atenção primária: dificuldades no cuidado de pessoas com doenças crônicas não transmissíveis. Trabalho, Educação e Saúde, 15(2), 599-615. http://dx.doi.org/10.1590/1981-7746-sol00056.

Silva, C. G., Sena, L. B., Rolim, I. L. T. P., Souza, S. M. S., \& Sardinha, A. H. L. (2017). Cuidados de enfermagem a pacientes com condições crônicas de saúde: uma revisão integrativa. Revista Cuidado é Fundamental, 9(2), 599-605. http://dx.doi.org/10.9789/2175-5361.2017.v9i2.599-605.

Smith, C. H., Graham, C. A., \& Herbert, A. R. (2016). Respite needs of families receiving palliative care. Journal of Paediatrics and Child Health, 53(2), 17379. http://dx.doi.org/10.1111/jpc.13324.

Sousa, L., Marques-Vieira, C., Severino, S., \& Antunes, V. (2017). Metodologia de revisão integrativa da literatura em enfermagem. Revista Investigação Enfermagem, 20(1), 17- 26. <file://C:/Users/Igor/Downloads/MetodologiadeRevisoIntegrativaRIE21_17-26\%20(2).pdf>. 
Research, Society and Development, v. 10, n. 2, e7310212151, 2021

(CC BY 4.0) | ISSN 2525-3409 | DOI: http://dx.doi.org/10.33448/rsd-v10i2.12151

Vázquez, A. C. R., Luís, M. M., Melero, N. C. M., Mascaró, P. E. P., \& García, J. M. (2016). Caracterización del cuidador primario de enfermo oncológico en estado avanzado. Revista Cubana de Medicina General Integral. 32(3). 〈http://scielo.sld.cu/pdf/mgi/v32n3/mgi07316.pdf>. 